\title{
Violência, luta e resistência: historicidade da educação rural à educação escolar indígena
}

\author{
Leni Barbosa Feitosa ${ }^{1}$, Idemar Vizolli ${ }^{2}$ \\ ${ }^{1}$ Universidade Federal do Tocantins - UFT. Programa de Pós-Graduação em Educação. Quadra 109 Norte, Avenida NS15, \\ ALCNO-14 - Plano Diretor Norte. Palmas-TO. Brasil. ${ }^{2}$ Universidade Federal do Tocantins - UFT. \\ Autor para correspondência/Author for correspondence: lenifeitosa@uft.edu.br
}

\begin{abstract}
RESUMO. Este artigo objetiva deslindar, por meio da historicidade da escola ofertada aos povos indígenas, como a perspectiva da educação rural, pretendida com veemência, andarilhou para educação escolar indígena e como os seus modos próprios de pensar, produzir e expressar conhecimentos que emanam de suas culturas foram sendo legitimados e valorizados no ambiente escolar, à luz de uma revisão de literatura e análise documental. $\mathrm{O}$ andarilhar das perspectivas educacionais perpassou por uma historicidade evidenciada pela violência da imposição cultural eurocêntrica ao vislumbrar que o limiar da oferta escolar aos povos indígenas entremeava arranjos estratégicos dos invasores europeus para torná-los úteis ao país; e luta e resistência dos povos indígenas para ressignificar no ambiente escolar o processo de ensino e aprendizagem em seus territórios, alinhando-os à educação tradicional de seu povo. A categoria escola indígena foi legitimada somente a partir do reconhecimento da organização social, costumes, línguas, crenças e tradições, instituída pela Constituição Federal de 1988 e oficializada em 1999 por meio do Parecer $n^{\circ}$ 14/1999 e Resolução $n^{\circ}$ 03/1999. É relevante destacar que, o advento da educação escolar indígena resulta não do bem querer do Estado aos povos indígenas, mas de sua luta e resistência a inúmeras imposições culturais.
\end{abstract}

Palavras-chave: Violência, Luta e Resistência, Educação Escolar Indígena, Educação Rural. 


\title{
Violence, struggle and resistance: historicity of rural education to indigenous school education
}

\begin{abstract}
This article aims to identify, through the historicity of the school offered to indigenous peoples, the perspective of rural education, vehemently pursued, guided to indigenous school education and how their own ways of thinking, producing and expressing knowledge that emanate from their cultures were legitimized and valued in the school environment, in the light of a literature review and documentary analysis. The sidewalk of the educational prospects has undergone a historicity evidenced by the violence of the Eurocentric cultural imposition when envisaging that the threshold of the school supply to the indigenous peoples interweaved strategic arrangements of the European invaders to make them useful to the country; and struggle and resistance of the indigenous peoples to re-signify in the school environment the process of teaching and learning in their territories, aligning them with the traditional education of their people. The category of indigenous school was legitimized only from the recognition of social organization, customs, languages, beliefs and traditions, instituted by the Federal Constitution of 1988 and made official in 1999 through Opinion $n^{\circ}$ 14/1999 and Resolution $n^{\circ} 03 / 1999$. It is important to note that the advent of indigenous school education results not from the well-being of the State to indigenous peoples, but from their struggle and resistance to numerous cultural impositions.
\end{abstract}

Keywords: Violence, Struggle and Resistance, Indigenous School Education, Rural Education. 


\section{Violencia, lucha y resistencia: historicidad de la educación rural a la educación escolar indígena}

RESUMEN. Este artículo objetiva deslindar, por medio de la historicidad de la escuela ofrecida a los pueblos indígenas, como la perspectiva de la educación rural, pretendida con vehemencia, caminó hacia educación escolar indígena y como sus modos propios de pensar, producir y expresar conocimientos que emanan de sus culturas fueron siendo legitimados y valorados en el ambiente escolar, a la luz de una revisión de literatura y análisis documental. El caminar de las perspectivas educativas atravesó una historicidad evidenciada por la violencia de la imposición cultural eurocéntrica al vislumbrar que el umbral de la oferta escolar a los pueblos indígenas entremejaba arreglos estratégicos de los invasores europeos para hacerlos útiles al país; y lucha y resistencia de los pueblos indígenas para resignificar en el ambiente escolar el proceso de enseñanza y aprendizaje en sus territorios, alineándolos a la educación tradicional de su pueblo. La categoría escuela indígena fue legitimada solamente a partir del reconocimiento de la organización social, costumbres, lenguas, creencias y tradiciones, instituida por la Constitución Federal de 1988 y oficializada en 1999 por medio del Dictamen $n^{\circ}$ 14/1999 y Resolución $\mathrm{n}^{\circ}$ 03/1999. Es importante destacar que el advenimiento de la educación escolar indígena resulta no del bien querer del Estado a los pueblos indígenas, sino de su lucha y resistencia a innumerables imposiciones culturales.

Palabras clave: Violencia, Lucha y Resistencia, Educación Escolar Indígena, Educación Rural. 


\section{Introdução}

Lançando um olhar na historicidade da educação escolar indígena no Brasil, percebemos que por muito tempo a educação escolar esteve alicerçada no ensino substanciado na perspectiva rural, objetivando fazer-lhes aprender os modos de vida do campo para produzir e servir os invasores $^{\mathrm{i}}$, tornando-se dessa maneira, úteis ao país.

Várias medidas educacionais foram implementadas para esse fim, como a prática da tríade: aldeamento, catequese e educação. Coube aos jesuítas o limiar da sistematização dessa escola, implementada com vista ao ensino para ler e escrever em português, doutrinamento a conduta cristã e, sobretudo, fazer-lhes incorporar a prática agrícola fomentada nas atividades escolares de capacitação profissional.

A política portuguesa esteve projetada para oferta de uma educação tracejada na civilização, religião e mão de obra para o desempenho de diversas atividades a serem desenvolvidas na colônia. Conquanto, evidencia-se, por meio da literatura, que mesmo com toda a estruturação escolar intencionalizada para os propósitos dos europeus, vários grupos indígenas resistiram à sua incorporação ao trabalho compulsório.

Essa resistência não foi bem vista pelos invasores, dando início a diversos embates ideológicos que reverberavam a possibilidade de exterminar os indígenas relutantes ao desempenho laboral, motivado pela presunção da impossibilidade de sua assimilação aos costumes de Portugal (Cunha, 2012).

Nesse contexto, a coroa portuguesa implementou várias políticas para dirimir que a resistência dos povos indígenas florescesse, dentre elas, a Lei de Terras instituída em 1850, a qual estabelecia a devolução dos territórios dos aldeamentos não registrados ao governo para serem disponibilizados à venda, forçando muitos indígenas a viverem como posseiros (Gomes, 1988).

Mesmo com a criação do Serviço de Proteção aos Índios em 1910, a oferta da educação escolar continuou alicerçada, talvez de maneira mais branda, para preparar os povos indígenas à vida rural, aproximando-os do contexto pretendido pelo governo: a vida no campo, seus meios de produção e desempenho laboral assalariado ou como produtor rural.

A perspectiva escolar de atrelar aos indígenas $\mathrm{o}$ sentido do trabalho foi prosseguida pela Fundação Nacional do Índio (FUNAI), criada em 1967 para substituir o antigo órgão. Nesse contexto, este artigo objetiva deslindar, por meio da historicidade da escola ofertada aos povos indígenas, como a perspectiva da educação 
rural, pretendida com veemência, andarilhou para educação escolar indígena e como os seus modos próprios de pensar, produzir e expressar conhecimentos que emanam de suas culturas foram sendo legitimados e valorizados no ambiente escolar, à luz de uma revisão de literatura, sistematizada por meio de artigos científicos, livros, dissertações e teses, bem como análise documental de normativas educacionais instituídas a partir da Promulgação da Constituição Federal de 1988, Decreto Presidencial $n^{\circ}$ 26/1991, Portaria Interministerial MJ/MEC $\mathrm{n}^{\circ}$ 559/1991, Portaria Ministerial n 60/1993, Lei $n^{\circ}$ 9.394/1996, Referencial Curricular Nacional para Escolas Indígenas, Parecer CEB/CNE $n^{\circ} 14 / 1999$ e Resolução CEB/CNE ${ }^{\circ}$ 03/1999.

\section{Do silenciamento à vez e voz: o andarilhar da escola ofertada aos povos indígenas}

A educação escolar destinada aos povos indígenas inicia-se no período de invasão europeia portuguesa no século XVI, emergida e instrumentalizada na perspectiva da perda da identidade cultural. A oferta do ambiente escolar foi convencionada como uma estratégia de contato que possibilitou a aproximação entre invasores e indígenas.

Para além do subsídio de contato, a escola também serviu como mecanismo de imposição da cultura europeia aos povos indígenas. Ao considerarmos imposição cultural, estamos ponderando que o processo educacional contrapunha ao processo propriamente indígena, desconsiderando a cultura, línguas, costumes e tradições dos grupos indígenas.

Com a estruturação do ambiente escolar, vários grupos indígenas foram forçados a se deslocarem para os aldeamentos. Borsatto (2010, p. 25) explica que a "educação dos jesuítas era adjacente à catequese para a conversão à religião cristã, significando a imposição de uma nova cultura e supressão da indígena”. Essa perspectiva educacional foi utilizada para "promover a assimilação dos indígenas à civilização cristã, com o imperativo da língua, da história, dos valores e da identidade da sociedade cristã europeia”. (Markus, 2006, p. 59).

O ensino escolar prosseguia exclusivamente na assimilação: "perda das características próprias e sua substituição pelas do grupo dominante, que devem ser consideradas superiores". (Funari \& Pinón, 2016, p. 22). Nessa caracterização, Pinheiro (2012) elucida que as escolas indígenas se emolduraram na "submersão" constituindo um ambiente elencado por "três instrumentos: aldeamento, catequese e educação", uma vez que a intenção de ofertar a escola às comunidades indígenas 
perpassava o intuito educacional, estruturando-se em um modelo de negação a diversidade e injunção cultural. (Funari \& Pinón, 2016, p. 29).

A estruturação do plano de estudo jesuítico baseava-se, primeiramente, na aprendizagem da fala da língua portuguesa no intento de assimilar os costumes dos invasores, prosseguindo o doutrinamento de estudos a conduta cristã. Com os primeiros ensinamentos, instruía-lhes a "ler e escrever, prosseguindo com a aprendizagem agrícola e gramática latina". (Ribeiro, 1964, p. 24).

$\mathrm{Na}$ escola prestigiavam o ensino da língua portuguesa e da matemática, objetivando, respectivamente, fazê-los escrever e pronunciar corretamente o português e desenvolver o potencial indígena para realizar as operações fundamentais de soma, subtração, divisão e multiplicação preparando-os para negociar a extração das riquezas naturais com os invasores.

As aprendizagens destinadas às técnicas para o trabalho braçal eram realizadas nas atividades escolares de capacitação profissional. Essas sucediam de maneira distinta entre homens e mulheres. Para os homens eram ofertados os cursos de "carpintaria, ferraria, mecânica, sapataria, eletricidade e tipografia", sendo distribuídos de acordo com suas habilidades, enquanto para as mulheres, os cursos concerniam em aprendizagens para a realização do "bordado, corte, costura, arte, culinária e cuidado com crianças", não havendo distinção de curso uma vez que para as mulheres essas habilidades eram consideradas fundamentais. (Melià, 1979, p. 50).

As crianças eram classificadas e enquadradas em grupos que seguiam critérios de propensão às atividades ofertadas como: trabalhos agrícolas, ensino das letras e educação profissional. Incluíase no primeiro grupo aquelas consideradas inabilitadas para as artes, matemática e letras; no segundo grupo as crianças com desenvoltura para a escrita e leitura e, no terceiro grupo, aquelas com habilidade para a atividade profissional (Oliveira, 2004).

Com o passar dos tempos, a prática educacional jesuítica foi considerada insatisfatória, ao perceber que a essência indígena era “intocável”, sendo a religião incapaz de mudar suas crenças (Melià, 1978, p. 53). Ribeiro (1992) menciona que a missão também foi considerada uma barreira para os invasores, principalmente porque era depositária de "um grande poder econômico, que deveria ser devolvido à coroa". (Ribeiro, 1992, p. 3334). Essa situação resultou na dispensa e 
expulsão dos jesuítas em 1759, bem como na confiscação de todos os seus bens e desativação dos aldeamentos no território neobrasileiro (Garcia, 2007).

Após treze anos da expulsão dos jesuítas, a coroa portuguesa "tomou a seu cargo a gestão das escolas", dando início à reconstrução da reforma do ensino na colônia apresentando grandes mudanças estruturais, todavia, com a mesma "tradição pedagógica jesuítica e seus valores essenciais". (Azevedo, 1944, p. 312-315).

O ensino para os indígenas tornou-se obrigatório e exclusivo na língua portuguesa, proibindo o uso de suas línguas no ambiente escolar (Oliveira, 2012). Garcia (2007) menciona que foram incrementadas as escolas para educar os indígenas: colégios para os homens e recolhimento para as mulheres. A perspectiva da diferenciação do ambiente formativo, segundo Oliveira (2012), foi estabelecida no alicerce das atribuições sociais e religiosas europeias exercidas na época por homens e mulheres.

O processo educativo foi estruturado na rigorosidade disciplinar, injunção religiosa e ofício social adstritos ao modelo educacional jesuíta. A rigorosidade disciplinar perfazia desde o acordar ao deitar, apresentando-se na perspectiva de dinamizar o processo de assimilação com uma rotina de deveres e obediência a quem dispõe. A injunção religiosa refletia-se no prisma de oração que se devia fazer no primeiro e no último ato do dia, instituída como meio de lograr a salvação e o ofício social moldurado em atividades a serem desempenhadas por homens e mulheres. Nesse intento, os meninos eram capacitados para influência da pronúncia, escrita, leitura e interpretação da língua portuguesa, já que para as meninas bastava-lhes a influência da fala em português para o entendimento e diálogo, com vistas a desempenharem todas as atividades domésticas essenciais para ordenar uma casa.

Almeida (2010) explica que, simultaneamente a oferta do ensino escolar para civilizá-los, ocorriam muitas disputas por novas terras e diligência por escravos indígenas, ocasionando inúmeros conflitos entre invasores e indígenas. Os invasores intencionados em submetê-los ao seu comando em nome do Rei de Portugal, e os indígenas pela resistência em serem escravizados.

Desde o fim do século XVIII até meados do século XIX foram constantes os debates para decidirem se deveriam "exterminar os indígenas bravos, desinfetando os sertões". (Cunha, 2012, p. 57). Situação motivada pelos invasores que presumiam a impossibilidade de 
assimilação dos indígenas aos costumes de Portugal, sobretudo ao evidenciarem a sua resistência à incorporação como mão de obra.

A resistência ao trabalho compulsório nas atividades coloniais levou estadistas a constantes questionamentos acerca do processo de assimilação, bem como sobre os procedimentos de conduta para o seu êxito: usar de "brandura ou de violência", ou seja, estabelecer guerra ou paz com os indígenas (Cunha, 2012, p. 57).

Nesse contexto histórico, havia polarização ideológica, uns sinalizavam pela paz, outros pela guerra. Os argumentos que resguardavam essas convicções sucederam respectivamente, como mencionam Azanha e Valadão (1991) de que os indígenas deveriam ser "protegidos" em suas terras aldeadas, uma vez que agiam como "crianças", e castigados para aprender a ter obediência às "regras da sociedade dominante". (Azanha \& Valadão, 1991, p. 36).

O embate ideológico a respeito das estratégias de assimilação dos indígenas foi vislumbrado na apropriação das terras reservadas a eles. Os argumentos que rodeavam os recursos emanavam num contexto de divergência. Para uns, os indígenas "são errantes, que não se apegam ao território, que não têm noção de propriedade, não distinguindo o "teu" do "meu." Para outros, os indígenas sendo “errantes ou não, conservam a memória e o apego a seus territórios tradicionais". (Cunha, 1992, p. 142).

Destituídos os povos indígenas de direitos constitucionais, Azanha \& Valadão (1991) mencionam que a latência dos interesses econômicos viabilizou em 1850 na criação da Lei de Terras. Essa instituía a devolução dos territórios dos aldeamentos não registrados ao governo para serem disponibilizados à venda. Cunha (2012) explica que esse dispositivo "inaugura uma política agressiva em relação às terras das aldeias". (Cunha, 2012, p. 79).

Resultante desse preceito, em 1860 foi criado o Ministério de Agricultura para dirimir as políticas indigenistas. Segundo Gomes (1988), com essa gerência “dezenas de aldeias... foram extintas formalmente, e os seus habitantes condenados a virarem posseiros sem terras e a perderem suas características culturais específicas". (Gomes, 1988, p. 81).

Com essa situação, o pensamento de extermínio dos indígenas se solidificava principalmente pelo discurso dos invasores de que eles eram inaptos à "evolução humana”. Sob outra perspectiva, acontecia uma manifestação internacional de "inoperância" do governo brasileiro quanto aos direcionamentos políticos na "defesa 
do patrimônio indígena”. (Gomes, 1988, p. $82)$.

Para Azanha e Valadão (1991, p. 42), "o ideal do império prolonga-se na república" e a Constituição de 1891 nada dispõe sobre os direitos dos povos indígenas. $\mathrm{O}$ rebuçar das prerrogativas constitucionais e a efervescência dos conflitos entre indígenas e invasores europeus alargaram adeptos e destoantes acerca da questão indígena. Gomes (1988, p. 84) menciona que os adeptos requeriam a proteção dos povos indígenas deliberada pelo Estado, bem como o anteparo das terras que compunha os aldeamentos. Já os destoantes propunham o "extermínio" dos indígenas justificando que sua presença no território impedia o progresso brasileiro.

$\mathrm{O}$ autor ainda enfatiza que a alegação dos destoantes teve repercussão internacional, e a questão indígena no território brasileiro esteve presente nos tópicos do XVI Congresso dos Americanistas ocorrido em Viena em 1908. Cunha (2012) menciona que o Brasil foi publicamente acusado de massacrar os indígenas e Lima (1992, p. 156) explica que essa arguição propiciou vários debates públicos de "amplas proporções contra um pretenso projeto de extermínio das populações indígenas no Brasil". Essas denúncias resultaram no âmbito nacional na institucionalização, ainda em 1909, do
Ministério da Agricultura, Indústria e Comércio (MAIC) e, em 1910, na criação do Serviço de Proteção aos Índios e Localização dos Trabalhadores Nacionais (SPILTN), por meio do Decreto $8.072 / 1910$, ficando subordinado ao MAIC.

Sirqueira e Sousa (2005, p. 5) elucidam que a criação do SPILTN foi um movimento político com ênfase em "conciliar os interesses do desenvolvimento capitalista e a preservação da vida indígena..., pacificar as tensões sociais... e também uma resposta do governo à opinião pública e aos movimentos sociais". O intento nuclear do Estado, na compreensão de Azanha e Valadão (1991), entremeava na melhoria da imagem internacional do Brasil no tratamento aos indígenas. Nessa perspectiva atribuiu ao órgão: a localização dos trabalhadores nacionais; pacificação e proteção dos grupos indígenas; demarcação de terras; criação de reservas indígenas; organização dos núcleos de colonização, com base na mão de obra sertaneja e gerenciamento da educação e catequese dos povos indígenas.

Para esta incumbência, o Coronel Cândido Mariano da Silva Rondon foi convidado para fundar e gerir o SPILNT em virtude da harmonização que se pretendia ao órgão aos "ideais positivistas 
da época". (Markus, 2006, p. 62). Segundo Azanha e Valadão (1991, p. 46), Rondon reverberava que "os brancos eram os invasores" e os indígenas só atacavam para "preservar suas terras" e, por conseguinte, deveriam ser respeitados.

As diretrizes do SPILTN alicerçaram no lema justiça e brandura, na perspectiva de tencionar um generoso anteparo frente aos conflitos pelas terras com os imigrantes europeus, mas substanciavam no instruir os indígenas para as atividades do trabalho rural (Sirqueira \& Sousa, 2005). Ademais, agregam os autores, o órgão abrigava duas instituições com intentos administrativos e operacionais antagônicos: proteção dos indígenas e incorporação ao trabalho nacional. Com a discrepância institucional em 1918, por meio do Decreto $n^{\circ} 3.454 / 1918$ o governo instituiu a desvinculação das atividades de Levantamento de Trabalhadores Nacionais, ficando o SPI com desígnio específico de proteger as comunidades indígenas no território brasileiro (Lima, 1992).

Em relação às estratégias educacionais, o SPI decide que a escola para o indígena não poderia ser ofertada com apenas uma proposta pedagógica, mas em várias. Estas deveriam se diferenciar em "forma e em programa educativo", em decorrência dos diferentes níveis de incorporação dos grupos indígenas à civilização nacional. Isto posto, dispôs de três categorias de escola, classificando-as de acordo com o nível de aculturação: mais aculturado, menos aculturado e não aculturado. (Ribeiro, 1964, p. 156).

O âmago do ensino seguiu os padrões das escolas rurais brasileiras. Para os indígenas aculturados, o ensino tencionava em aproximá-los da vida do campo e seus meios de produção no sentido de prepará-los para o desempenho laboral assalariado ou como produtor rural. Aos menos aculturados, elevá-los como seres humanos dignos do convívio nacional e defensores de sua pátria, bem como ensinar às crianças a falar um português sem sotaque e incentivá-los a prática de higiene estabelecida pelo ocidente. Aos não aculturados, o propósito foi manter um contato educativo despretensioso da imposição de incorporação, aguardando que ela ocorresse espontaneamente ao respeitar os seus costumes, inclusive a língua falada por eles, mas o ensino não estava escuso do aprendizado da oralidade sem sotaque do português, práticas de higiene europeia e do respeito à pátria nacional (Ribeiro, 1964).

Com essas medidas, o peso da integração aos povos indígenas a sociedade nacional estava posta. As categorias dos programas educacionais na compreensão de Ribeiro (1964) expressaram claramente 
a prática sofrida pelos diversos grupos indígenas e seus efeitos "desmoralizantes", uma vez que o processo de assimilação e posteriormente de integração não os inseriu em contexto neobrasileiro, tampouco valorizou sua presença no cotidiano nacional, mas descaracterizou "seu corpo de valores" e marginalizou sua presença no meio social, tornando muitos indígenas "tristes e desacreditados de si mesmos". (Ribeiro, 1964, p. 157).

Luciano (2006) refere que nesse contexto educacional, pouco a pouco foram surgindo as "primeiras escolas indígenas mantidas pelo Governo Federal", sendo que essas se distinguiam das escolas jesuíticas somente pelo ínfimo destaque ao ensino religioso, visto que os moldes educacionais eram fundamentados em regimentos rudimentares $\mathrm{e}$ descontextualizados ao modo de vida indígena, com alfabetização em português e proeminência ao trabalho agrícola para os homens e doméstico para as mulheres (Luciano, 2006, p. 150).

As escolas começaram a ser mantidas pelo Governo Federal em cumprimento à Constituição de 1934, a primeira a promulgar leis sobre os povos indígenas, subscrevendo a competência privativa da União para legislar sobre a incorporação dos silvícolas a comunhão nacional. A Constituição de 1937 subsiste a incumbência da União com os indígenas e instituiu em 1939, a subordinação do SPI ao Ministério da Agricultura, para que desenvolvesse práticas educativas alinhadas à produção agrícola (Lima, 1992). Para Oliveira (1947), com essa mudança, a questão indígena foi tradada como "questão de colonização", orientando-os ao interesse do "cultivo do solo, para se tornar úteis ao país", princípios perseverados na Constituição de 1946. (Oliveira, 1947, p. 171).

Em 1967, por meio da Lei $n^{\circ}$ 5.371/1967, o governo militar criou a FUNAI em substituição ao SPI, subordinando-a ao Ministério do Interior. Para Gomes (1988), o recente órgão indigenista "veio para resolver a questão indígena de uma vez por todas", uma vez que a dinamização dos povos indígenas a integração nacional estava sendo posta com veemência. $\mathrm{O}$ autor ainda menciona que as diretrizes operacionais da FUNAI seguiam alinhadas com as determinadas pelo antigo órgão, sob a justificativa de que o Estado havia determinado eficiência e prontidão às atividades de atrelar aos indígenas o "sentido do trabalho" e que as ações já realizadas com êxito deveriam ser prosseguidas. (Gomes, 1988, p. 87).

$\mathrm{Na}$ diligência do propósito a que se tencionava ascender, a FUNAI, entre outras finalidades, institui a promoção da 
"educação de base apropriada do índio visando à sua progressiva integração na sociedade nacional”. (Brasil, 1967, p. 1). Mesmo havendo o desígnio educacional por parte da FUNAI, Cunha (2012) ressalta que os destoantes entre os intentos da FUNAI e Ministério do Interior comprometeram a oferta escolar aos indígenas. À vista disso, a autora explica que essa junção sucedeu intencionalmente pelo governo, em virtude da incitação de discursos que reverberavam que eles eram obstáculos à prosperidade do país.

No campo educacional, Costa (2002) expressa que a Constituição de 1967 designa a competência da União no estabelecimento e execução dos planos nacionais de educação, na legislação sobre as diretrizes e bases da educação nacional, bem como define a autonomia educacional dos estados e municípios. Todavia, no que tange à educação escolar indígena, nada foi explicitado sob o argumento de que as diretrizes educacionais para os povos indígenas eram de incumbência exclusiva da FUNAI.

No início da década de 1970, conforme Oliveira e Freire (2006), as reivindicações dos indígenas à FUNAI sucediam de maneira estremada e pontual às problemáticas do grupo, isso não se tratava de questões meramente administrativas, mas sim estratégicas para dificultar as relações de contato entre os grupos étnicos para impedir a união e mobilização dos grupos contra o Estado. Essa prática perseverou até a divulgação da minuta do decreto em 1978, que indicava a emancipação dos indígenas e, por conseguinte, a retirada da tutela do Estado brasileiro.

Imbuídos na reflexão que isolados eram vulneráveis as ações políticas do governo, mas unidos eram impetuosos, as lideranças indígenas começaram a se organizar constituindo uma "comunidade" com uma "identidade supra-étnica" (Matos, 2006, p. 35). Oliveira e Freire (2006) compreendem a composição identitária como uma estratégia de instrumentalização da "categoria índio" na perspectiva de representar a articulação do movimento, unificando suas "reivindicações e lutas por direitos" reluzidas pela União Nacional do Índio (UNI). (Oliveira \& Freire, 2006, p. 193).

A efervescência social indígena, segundo Santana (2011), cresce exponencialmente e o movimento de luta pela ressignificação da escola ofertada a eles se robustece no reflexo de que se por muito tempo a escola esteve sob a égide da negação de seus saberes tradicionais, nesse momento ela deveria insurgir como um ambiente favorável para o empoderamento e autonomia dos povos indígenas. 
Silveira e Silveira (2012) enfatizam que as lutas dos movimentos indígenas para atribuir um novo significado a escola tracejaram na "busca do resgate dos valores étnicos". (Silveira \& Silveira, 2012, p. 29). Com essa proposição educacional, Oliveira (2012) evidencia que ela se tornou a bandeira para sobrevir as “concepções de educação baseadas nos processos tradicionais de educação das sociedades indígenas". (Oliveira, 2012, p. 49).

Com a articulação do movimento indígena que contava com apoio do movimento indigenista e sociedade civil, foram apresentadas, em 1987, propostas para a Assembleia Nacional Constituinte e à Lei de Diretrizes e Bases da Educação Nacional. Conquanto, o movimento indígena não ficou esperando o resultado da votação de suas proposições e organizaram uma "vigília permanente no Congresso Nacional”, objetivando acompanhar e pressionar "os congressistas a reconhecerem suas reivindicações", findando somente após a promulgação da Constituição Federal de 1988 (CF/1988) (Oliveira \& Freire, 2006, p. 194-195).

Os frutos da organização do movimento indígena $\mathrm{e}$ a respectiva articulação das entidades indigenistas e sociedade civil propiciaram conquistas significativas para os povos indígenas, a qual Ferreira (2001, p. 100) destaca como substancial "o direito a diversidade cultural". Proeminência corroborada por Azanha e Valadão (1991), ao elucidarem que por vários séculos a "condição de índio" foi tratada pelo Estado como uma situação "passageira, não definitiva", assim a legitimidade constitucional perfez um divisor de águas ao reconhecer a composição pluriétnica do Brasil. (Azanha \& Valadão, 1991, p. 86).

Nesse novo contexto, Grupioni (2002) explica que o papel da União com os povos indígenas foi ressignificado não lhe cabendo mais a incumbência de “incorporá-los" à comunhão nacional, mas dispor do compromisso de "legislar" sobre as populações indígenas no desígnio de protegê-las. (Grupioni, 2002, p. 121).

Para ascender proteção aos indígenas tornava-se basilar o reconhecimento de sua organização social. No teor da CF/1988 foi estabelecido no Capítulo VIII, intitulado “Dos Índios” o artigo 231 que reconhece "sua organização social, costumes, línguas, crenças e tradições, e os direitos originários sobre as terras que tradicionalmente ocupam, competindo à União demarcá-las, proteger e fazer respeitar todos os seus bens". (Brasil, 1988, p. 62).

Cordeiro (1999) esclarece que os escritos desses artigos constitucionais 
propõem um novo olhar a interpelação dos indígenas no território nacional, uma vez que vereda pela tríade de valorizar, preservar e desenvolver o "patrimônio cultural indígena" assentando o "reconhecimento de que a posse indígena da terra decorre de um direito originário, que por isso independe de titulação". (Cordeiro, 1999, p. 70).

No âmbito educacional, Markus (2006) destaca a valiosa solidez de erigir uma educação diferenciada ao substanciar no ambiente escolar seus processos próprios de ensino e aprendizagem, bem como o uso de suas línguas, na perspectiva da continuidade de seus costumes. Esse vislumbre foi garantido na CF/1988, entretanto, na ótica do movimento indígena obter a legalidade Constitucional, consistia em uma etapa vencida, mas outra deveria ser conquistada, a sua efetivação.

Desguarnecida de preceitos para nortear $\mathrm{o}$ seu funcionamento $\mathrm{e}$ intencionado em concretizar seus direitos, o movimento indígena amparado na $\mathrm{CF} / 1988$, intensificou a realização de assembleias em todo o país. O fervor que se destinavam nos encontros indígenas e não indígena permeava, entre outros assuntos, ao debate sobre a educação escolar, que ressoava na concretização imediata de programas bilíngues, autênticos, diferenciados e específicos (Ferreira, 2001).

Ainda segundo a autora, as discussões acerca da educação escolar adelgaçavam a insatisfação quanto à escolarização ofertada pela FUNAI e missões religiosas, sobretudo pela intransigência, imposição de valores alheios e negação de identidades culturais decorrentes da legislação integracionista. $\mathrm{O}$ novo contexto constitucional, alicerçado no reconhecimento das identidades indígenas, outorgava a desconstrução e reconstrução paradigmática da escola em seus territórios. No entanto, para a sua realização tornava-se imprescindível balizar um plano jurídico na perspectiva de normatizar a implantação desses novos parâmetros educacionais, bem como prover os recursos financeiros para a sua execução.

A educação escolar ansiada pelos povos indígenas estorvava o paradigma de injunção e alvitrava processos educacionais diferenciados e entremeados no cerne da cosmovisão dos grupos indígenas, com vistas à reafirmação de seus costumes, crenças e tradições. Baniwa (2009) explica que, resguardado desses princípios educacionais, o movimento indígena também concebeu a educação escolar como uma das estratégias de obter, por meio do processo de escolarização, 
conhecimentos da sociedade nacional, no intuito de apropriar-se de suas ferramentas políticas na luta pela efetivação de seus direitos constitucionais.

A partir da década de 1990, os instrumentos legais começaram a ser construídos, no intuito de materializar os alvitres garantidos pela Carta Magna. No âmbito educacional, as normativas iniciaram em 1991, por meio do Decreto Presidencial $n^{\circ}$ 26/1991 determinando ao Ministério da Educação (MEC) a competência para coordenar as ações referentes à educação escolar para os povos indígenas, em todos os níveis e modalidades de ensino, ouvida a FUNAI, bem como atribuiu a sua execução as secretarias de educação dos estados e municípios, em consonância com as Secretarias Nacionais de Educação do MEC (Brasil, 1991).

Promover a interlocução para operacionalizar a educação escolar indígena com estados e municípios, para estandardizar, catalisar e garantir o atendimento escolar às comunidades indígenas interessadas em recebê-las, sem a interferência local na gestão escolar, revelou-se como uma ação afável do órgão governamental. Entretanto, Pinheiro (2012) ressalta que a prática de estadualização e municipalização ocorreu “... sem a criação de mecanismos que assegurassem uma uniformidade de ações para garantir as especificidades destas escolas", ocasionando vários desencontros com o processo educativo almejado pelos movimentos indígenas e indigenistas. (Pinheiro, 2012, p. 45). Acerca disso, Grupioni (2008, p. 44) agrega que o desígno do decreto em instituir a "responsabilidade direta" das escolas indígenas sob o esteio das secretarias de educação estaduais e municipais, refutou a expectativa de que o "MEC seria o novo gestor das escolas indígenas".

Descontente com o cenário educacional estruturado pelo MEC, e, sobretudo pela ausência dos povos indígenas no ato de transferência institucional, e na sistematização da educação escolar, os movimentos indígenas e indigenistas realizaram vários protestos para pressionar o governo federal a assentir sua participação nas deliberações acerca da educação escolar, alegando temer que as ações operacionais instituídas pelo órgão pudessem pôr em risco a sua sobrevivência, enquanto povos diferenciados (Ferreira, 2001).

A solicitação dos movimentos foi atendida. E os representantes dos povos indígenas fizeram-se presentes nas discussões que envolviam a educação escolar. Ainda em 1991, os Ministérios da Justiça e Educação regulamentaram a 
competência do MEC para coordenar as ações no âmbito da educação escolar indígena, por meio da Portaria Interministerial MJ/MEC $\mathrm{n}^{\circ} 559 / 1991$, a qual Ferreira (2001, p. 84) vislumbra contemplar "grande parte das reivindicações" do movimento indígena.

Essa portaria normatiza a educação escolar indígena e salvaguarda as especificidades dos grupos étnicos ao mencionar: que o ensino bilíngue deve ser substanciado na língua materna de cada comunidade indígena e na oficial do país; promoção de formação de professores; articulação entre os conteúdos curriculares, calendário escolar, metodologias, avaliação e material didático. Ademais, são garantidos o reconhecimento das escolas destinadas às comunidades indígenas; a continuidade de escolarização em aldeias que não dispõe da oferta do ensino médio e inclusão das ações de educação indígena no Plano Nacional de Educação (Brasil, 1991).

Para Ferreira (2001, p. 85), a normatização permeia no cerne constitucional, sobretudo por garantir a educação bilíngue, específica e diferenciada. Todavia, tece questionamentos ao dispositivo por depreciar as "concepções de educação escolar", com base nos processos próprios de ensino e aprendizagem dos grupos indígenas, quando não definiu quem ficaria "responsável pela elaboração dos Programas de Educação Indígena”. A lacuna deixada por essa portaria norteou os debates do movimento indígena na reivindicação do direito à autodeterminação também em relação à educação escolar.

Entremeio a essa discussão, o MEC cria o Comitê de Educação Escolar Indígena (CEEI) em 1992, por meio da Portaria Ministerial $n^{\circ}$ 60/1993, para "subsidiar as ações e proporcionar apoio técnico-científico às decisões que envolvia a adoção de normas e procedimentos relacionados com o Programa de Educação Escolar Indígena”. (Brasil, 1992, p. 1).

Com o CEEI estruturado em 1993, elaborou-se as Diretrizes para a Política Nacional de Educação Escolar Indígena (DPNEEI). De acordo com Grupioni (2008, p. 53), as diretrizes principiam as políticas públicas da educação escolar indígena sob “influência direta de dispositivos que constam na Constituição de 1988", promovendo um "novo modelo de escola indígena que se pretendia implantar no país".

$\mathrm{Na}$ diligência de pôr em prática os desígnios das diretrizes e romper definitivamente $\mathrm{o}$ modelo educacional integracionista, o MEC realizou várias reuniões, encontros e seminários com as 
secretarias estaduais e municipais de educação, membros do CEEI, professores indígenas, representantes de organizações não governamentais e pesquisadores de universidades, para sistematizar os mecanismos a serem operacionalizadas na concretização da escola indígena.

Um valoroso realce da normativa enfatizada por Oliveira (2012) perfaz os princípios gerais, ao estabelecer a vinculação das práticas pedagógicas às especificidades e a diferença, a interculturalidade, a língua materna, ao bilinguismo e a integração do processo de aprendizagem. $\mathrm{O}$ autor menciona que dentre outros documentos que tratam da educação escolar indígena, esse foi o primeiro a mencionar a expressão interculturalidade, especificando-o como "o intercâmbio positivo e mutuamente enriquecedor entre as culturas das diversas sociedades, que deve ser característica básica da escola indígena”. (Brasil, 1993, p. 11).

Em uma concepção dinâmica, a configuração normativa para a educação escolar indígena foi sendo moldada, e em 1996, por meio da Lei $n^{\circ} 9.394 / 1996$, os dispositivos estabelecidos pela Carta Magna são regulamentados no âmbito da educação nacional. Esse preceito, conhecido como Lei de Diretrizes e Bases da Educação (LDB), determinou em seus princípios norteadores do ensino nacional, o "pluralismo de ideias e de concepções pedagógicas" (Brasil, 2017, p. 1). Para Berg, Albuquerque e Pojo (2008, p. 14), esse princípio garante às "escolas indígenas um processo educativo diferenciado e respeitoso de sua identidade cultural e bilíngue”. Bonin (2012) menciona que esta lei estabeleceu as atribuições de "organizar a educação escolar indígena”, assumindo a obrigação de “assegurar proteção e respeito às culturas e modelos próprios de educação indígena”. (Bonin, 2012, p. 100).

Silveira e Silveira (2012, p. 57) mencionam que esse preceito reforça a construção da "educação intercultural e bilíngue" como direito constitucional, todavia tecem crítica no rebuçar textual ao apresentar com sutileza "a imposição da língua oficial" aos povos indígenas.

Por conseguinte, o título VIII da LDB intitulado Das Disposições Gerais aprecia a educação escolar indígena nos artigos 78 e 79 . $\mathrm{O}$ artigo 78 dispõe sobre o desenvolvimento de programas integrados de ensino e pesquisa para a oferta da educação escolar bilíngue e intercultural aos povos indígenas, no intento de recuperar suas memórias históricas, reafirmação de suas identidades étnicas e valorização de suas línguas e ciências. Assim como garante o acesso às 
informações, conhecimentos técnicos e científicos das sociedades indígenas e não índias (Brasil, 2017).

O artigo 79 trata do apoio técnico e financeiro do sistema de ensino no provimento da educação intercultural aos povos indígenas, bem como no desenvolvimento de programas integrados de ensino e pesquisa, que serão planejados com audiências das comunidades indígenas e incluídos nos Planos Nacionais de Educação, objetivando fortalecer as práticas socioculturais e a língua materna; manter programas de formação de pessoal especializado; desenvolver currículos e programas específicos; assim como elaborar e publicar material didático específico e diferenciado (Brasil, 2017).

Vários instrumentos legais foram procedidos da LDB/1996 no intuito de instituir as mudanças operacionais e pedagógicas no cotidiano das escolas em territórios indígenas. Em 1998, o MEC elaborou o Referencial Curricular Nacional para Escolas Indígenas (RCNEI) para oferecer subsídios e orientações aos profissionais atuantes na educação escolar indígena, para a elaboração de programas de escolas com base na pluralidade cultural, equidade entre todos os povos brasileiros, criação e produção de materiais didáticos e formação de professores indígenas.
O RCNEI é considerado o primeiro instrumento institucional a apresentar ideias básicas e sugestões de trabalho para o conjunto das áreas do conhecimento de cada ciclo escolar das escolas indígenas inseridas no Ensino Fundamental (Brasil, 1998). Oliveira (2012) alude que "por ser novidade no campo da educação escolar indígena, o documento não teve a pretensão de ser um referencial fechado", mas aberto para a construção dinâmica de programas educacionais para os povos indígenas, substanciados nas experiências vivenciadas nas escolas, e assim, enaltecendo professores e comunidades à autoria do projeto escolar específico, diferenciado, bilíngue e intercultural. (Oliveira, 2012, p. 67).

Um avanço significativo do RCNEI foi a legitimação da educação intercultural, a qual Oliveira (2012) elucida abrolhar da ratificação do dispositivo referido na DPNEEI em 1993, na LDB/1996. O reconhecimento da educação intercultural no tecer da educação escolar indígena é tratado no RCNEI na perspectiva de "reconhecer e manter a diversidade cultural e linguística; promover uma situação de comunicação entre experiências socioculturais, linguísticas e históricas diferentes, não considerando uma cultura superior à outra ...”. (Brasil, 1998, p. 24). 
O ponto essencial da educação intercultural permeia em favorecer e entrelaçar diálogos e experiências socioculturais e linguísticas, proporcionando o enriquecimento entre culturas e arvorando o conhecimento histórico e social das diversas formas de manifestação cultural, na perspectiva de incitar não somente $\mathrm{o}$ respeito das múltiplas identidades étnicas, mas acima de tudo, sua valorização no deslindar de seus mecanismos, funções e dinâmicas.

No ano seguinte, 1999, dois instrumentos normativos são publicados pela Câmara de Educação Básica (CEB), vinculada ao Conselho Nacional de Educação (CNE), o parecer $\mathrm{CEB} / \mathrm{CNE} \mathrm{n}^{\circ}$ 14/1999, que aprovou as Diretrizes Curriculares Nacionais da Educação Escolar Indígena (DCNEEI) e, a Resolução CEB/CNE $n^{\circ}$ 03/1999 que fixou as Diretrizes Nacionais para o Funcionamento das Escolas Indígenas (DNFEI).

Um importante passo foi dado com as DCNEEI, sobretudo a oficialização da escola indígena no âmbito do MEC. Esse reconhecimento na compreensão de Oliveira (2012) se perfaz pelo amadurecimento concebido pelos diversos diálogos promovidos pelo MEC, com as instituições governamentais e não governamentais e, principalmente, pelos representantes indígenas, os quais expressaram com solidez, que no âmago de cada cosmovisão indígena há processos educativos próprios de produzir e transmitir seus conhecimentos.

Com a percepção diferenciada acerca da educação escolar e educação indígena, o preceito das DCNEEI principia com a compreensão do ensino e aprendizagem indígena, designada como "processo pelo qual cada sociedade internaliza em seus membros um modo próprio e particular de ser garantido sua sobrevivência e sua reprodução". (Brasil, 1999a, p. 3).

Com o olhar singular sobre a educação escolar indígena foram construídas as diretrizes. Essas foram consideradas fundamentais em decorrência das experiências escolares vivenciadas ao longo da história, alicerçadas na concepção assimilacionista e integracionista que perpetuaram imposição, dominação e negação das diferentes identidades dos povos indígenas e, sobretudo pela reelaboração de seus conhecimentos e concepções ao longo da história escolar.

É nesse contexto que a escola indígena floresce no âmbito dos sistemas oficiais da educação brasileira, amparada no reconhecimento da "diversidade sociocultural e linguística do país", bem como no "direito de sua manutenção", uma vez que antes era enquadrada e operacionalizada como escola rural ou 
como extensão de escolas rurais, "com calendários escolares e planos de cursos válidos para esse tipo de escola”. (Brasil, 1999a, p. 8-9).

A categorização da escola indígena nos termos jurídicos foi justificada no parecer do CNE, no escopo de permitir que ela seja respeitada e que efetivamente haja nos territórios indígenas um ambiente escolar específico e intercultural.

A circunspeção do parecer do CNE em resguardar os financiamentos públicos para promover a autonomia pedagógica e a participação dos membros da comunidade indígena, apresenta-se, segundo Gorete Neto (2009), imprescindível para garantir a oferta de uma escola diferenciada e específica, bem como favorecer os processos interculturais reputáveis para o convívio construtivo, ao estabelecer a interseção do conhecimento, valorização e aprendizagem com as diferenças.

Outra necessidade percebida para a aprovação do parecer foi a identificação do ponto de vista administrativo da escola indígena, no intuito de endossar o pleno direito aos diversos programas que visam os benefícios da Educação Básica oferecido pelo MEC. Nesse discernimento, a escola indígena é caracterizada como "estabelecimento de ensino localizado no interior das terras indígenas voltado para o atendimento das necessidades escolares expressas pelas comunidades indígenas". (Brasil, 1999a, p. 8).

No preceito das DCNEEI, elucida-se que a definição da escola indígena categorizava-se como primordial, uma vez que responsabiliza o sistema de ensino do MEC a traçar diretrizes e políticas para a educação escolar indígena, assegurando o "direito a uma educação de qualidade que respeite e valorize seus conhecimentos e saberes tradicionais e que permita o acesso aos conhecimentos universais, de forma a participares ativamente como cidadãos plenos do país”. (Brasil, 1999a, p. 1).

As questões relativas à formação do professor indígena; o currículo e sua flexibilidade; a condescendência das exigências das formas de contratação de professores indígenas; a estrutura da escola e a realização de ações concretas visando à implementação da educação escolar indígena, também são diretivas tratadas no parecer do CEB.

O professor indígena é considerado pelas DCNEI integrante essencial para a concretização das escolas em seus territórios, uma vez que as peculiaridades culturais só podem ser tratadas por membros que pertencem às sociedades envolvidas. Desta forma, prevê o desenvolvimento de pedagogias indígenas, a partir da realização de programas diferenciados de formação inicial e 
continuada de professores indígenas, estruturadas para desenvolver entre outras habilidades, a elaboração de currículos e produção de materiais didáticos específicos a escola da comunidade indígena.

$\mathrm{Na}$ perspectiva da flexibilidade do currículo, a intenção é proporcionar uma educação diferenciada, alicerçada na oferta da língua materna para promover o acolhimento das temáticas propriamente indígenas, bem como nos modos próprios de transmissão do saber. A concretização do currículo é certificada pela possibilidade de inserir conteúdos concebidos na base curricular diversificada, como por exemplo: língua materna, crenças, memórias históricas, saberes ligados à identidade étnica, as suas organizações sociais do trabalho, às relações humanas e manifestações artísticas.

$\mathrm{Na}$ condescendência das exigências das formas de contratação de professores indígenas, o documento normativo estabelece que seja instituída e regularizada a profissionalização do magistério indígena, no desígnio de oferecer condições adequadas de trabalho docente, remuneração compatível com as funções que exercem e formação adequada para o exercício do seu trabalho. Com a criação da categoria professor indígena, estabelece as formas de admissão à carreira do magistério, que poderá sobrevir por meio de concurso público, processo público de seleção ou contrato temporário, devendo suceder em plena sintonia com as particularidades linguísticas e culturais das sociedades indígenas.

A estrutura da escola indígena qualifica, em seu cerne, o reconhecimento legal da diversidade cultural dos povos indígenas e a convivência democrática dos diferentes segmentos que constitui a Nação brasileira. Isto posto, estabelece às secretarias estaduais de educação a responsabilidade de desenvolver em harmonia com professores e comunidades indígenas o currículo escolar, submetendo a determinação legal do cumprimento de duzentos dias letivos, com quatro horas diárias de atividade escolar, perfazendo oitocentas horas anual. Todavia ressalvando para que essa observância seja ajustada às condições e aos hábitos indígenas.

Para a dinâmica realização de ações concretas visando à implementação da educação escolar indígena, foram estabelecidas à participação dos sistemas de ensino da União, dos estados e dos municípios. Cabendo à União legislar sobre a educação escolar indígena e ao estado a sua execução em colaboração com seus municípios. 
As definições das competências a serem desenvolvidas pelos governos, federal e estadual, estruturam no plano institucional, administrativo e organizacional a oferta e o desenvolvimento das escolas indígenas. Conquanto, Bonin (2012) ressalta que embora haja o aparato legal que contemple essas atribuições, atualmente há um "pequeno número de escolas reconhecidas como indígenas, a maioria delas segue sendo consideradas escolas rurais, sem que se assegurem as diferenças e características próprias”. (Bonin, 2012, p. 42).

Com a indicação de normas para o funcionamento das escolas indígenas, bem como a construção dos currículos com base na educação intercultural, o CEB/CNE fixa as Diretrizes Nacionais para o Funcionamento das Escolas Indígenas (DNFEI), por meio da Resolução $n^{\circ}$ 03/1999.

Esse preceito trata dos elementos básicos para a organização, estrutura e funcionamento da escola indígena; formação de professores; o exercício da atividade docente e define as atribuições administrativas, organizacionais e financeiras entre os entes federativos com relação à educação escolar indígena.

Acrescidas a essas deliberações, o preceito estabelece no âmbito da Educação Básica a estrutura e o funcionamento das escolas indígenas, "reconhecendo-lhes a condição de escolas com normas e ordenamento jurídico próprio", assim como fixa as "diretrizes curriculares do ensino intercultural e bilíngue, visando à valorização plena das culturas dos povos indígenas e, a afirmação e manutenção de sua diversidade étnica". (Brasil, 1999b).

Substanciados nesses preceitos, vários instrumentos jurídicos e pedagógicos foram implementados, sendo os mais expressivos e representativos: Lei $n^{\circ} 10.172 / 2001$, Decreto Presidencial $n^{\circ}$ 17/2002, Decreto Legislativo no $143 / 2002$, Decreto Presidencial $n^{\circ} 5.051 / 2004$, Lei ${ }^{\circ}$ 11.645/2008, Decreto Presidencial $n^{\circ}$ 6.861/2009, Portaria MEC no $1.062 / 2013$ e Lei $\mathrm{n}^{\circ} 13.005 / 2014$, que visam garantir aos povos indígenas uma educação escolar bilíngue, específica, diferenciada e intercultural.

\section{Considerações finais}

É no entendimento de violência, luta e resistência de muitos povos indígenas que vislumbramos a historicidade da educação escolar. $\mathrm{O}$ andarilhar das perspectivas educacionais perpassou por uma historicidade evidenciada pela violência da imposição cultural eurocêntrica ao vislumbrar que o limiar da oferta escolar aos povos indígenas entremeava arranjos estratégicos dos 
invasores europeus para torná-los úteis ao país; e luta e resistência dos povos indígenas para ressignificar no ambiente escolar o processo de ensino e aprendizagem em seus territórios, alinhando-os à educação tradicional de seu povo.

A categoria escola indígena foi legitimada somente a partir do reconhecimento da organização social, costumes, línguas, crenças e tradições, instituída pela Constituição Federal de 1988 e oficializada em 1999 por meio do Parecer $n^{\circ}$ 14/1999 e Resolução $n^{\circ}$ 03/1999. É relevante destacar que, o advento da educação escolar indígena resulta não do bem querer do Estado aos povos indígenas, mas de sua luta e resistência a inúmeras imposições culturais de assimilá-los e integrá-los à sociedade nacional.

\section{Referências}

Almeida, M. R. C. (2010). Os índios na história do Brasil. Rio de Janeiro, RJ: FGV.

Azanha, G., \& Valadão, V. M. (1991). Senhores destas Terras: os povos indígenas no Brasil da colônia aos dias atuais. São Paulo, SP: Atual.

Azevedo, F. (1944). A cultura brasileira: introdução ao estudo da cultura no Brasil. São Paulo, SP: Companhia Editora Nacional.
Baniwa, G. (2009). Indígenas no ensino superior: novo desafio para as organizações indígenas e indigenistas no Brasil. Curitiba, PR: Nexo Design.

Berg, H. S., Albuquerque. M. S. G., \& Pojo, E. C. (2008). Fundamentos da Educação Indígena: Módulo 4. Brasília, DF: UNB.

Bonin, I. T. (2012). Educação escolar indígena e docência: princípios e normas na legislação em vigor. In Bergamaschi, M. A, Zen, M. I. H. D., \& Xavier, M. L. M. F. (Orgs.). Povos Indígenas e Educação (pp. 15-32). Porto Alegre, RS: Mediação.

Borsatto, F. S. (2010). Educação escolar indígena: construção curricular da escola estadual indígena krukutu (Dissertação de Mestrado). Pontifícia Universidade Católica de São Paulo, São Paulo. Recuperado de https://sapientia.pucsp.br/handle/handle/10 $\underline{796}$

Cordeiro, E. (1999). Política indigenista brasileira e promoção internacional dos direitos das populações indígenas. Brasília, DF: Instituto Rio Branco.

Costa, M. (2002). A educação nas constituintes do Brasil: dados e direções. Rio de Janeiro, RJ: DP\&A.

Cunha, M. C. (2012). Índios no Brasil: histórias, direitos e cidadania. São Paulo, SP: Claro Enigma.

Decreto Presidencial $n^{o} 26$ de 04 de fevereiro de 1991. Dispõe sobre a educação escolar indígena no Brasil. Recuperado de http://www.funai.org.br

Emenda Constitucional $n^{o} 1$, de 17 de outubro de 1969. Edita o novo texto da Constituição Federal de 24 de janeiro de 1967. Recuperado de http://www.Planalto.gov.br/ccivil_03/Conti 
tuicao/Emendas/Emc_anterior1988/emc01$\underline{69 . h t m}$

Ferreira, M. K. L. (2001). A educação escolar indígena: um diagnóstico crítico no Brasil. In Silva, A. L., \& Ferreira, M. K. L. (Orgs.). Antropologia, história e educação: a questão indígena e a escola (pp. 28-47). São Paulo, SP: Global.

Funari, P. P., \& Piñon, A. (2016). A temática indígena na escola: subsídios para professores. São Paulo, SP: Contexto.

Garcia, E. F (2007). O projeto pombalino de imposição da língua portuguesa aos índios e a sua aplicação na América Meridional. Revista Tempo, 12(23), 23-38. Recuperado de http://www.scielo.br/pdf/tem/v12n23/v12n $\underline{23 \mathrm{a} 03}$

Gomes, M. P. (1988). Os índios e o Brasil: ensaio sobre um holocausto e sobre uma nova possibilidade de convivência. Petrópolis, RJ: Vozes.

Gorete Neto, M. (2009). As representações dos Tapirapé sobre sua escola e as línguas faladas na aldeia: implicações para a formação de professores (Tese de Doutorado). Universidade Estadual de Campinas, Campinas. Recuperado de http://repositorio.unicamp.br/handle/REPO SIP/269780

Grupioni, L. D. B. (2002). Do nacional ao local, do federal ao estadual: as leis e a educação escolar indígena. In Marfan, M. A. (Org.). Congresso brasileiro de qualidade na educação: formação de professores (pp. 135-136). Brasília, DF.

Grupioni, L. D. B. (2008). Olhar longe, porque o futuro é longe: cultura, escola e professores indígenas no Brasil (Tese de Doutorado). Universidade de São Paulo, São Paulo. Recuperado de http://www.usp.br/nhii/biblioteca/LuisDoni sete.Grupioni2009.pdf
Lei $n^{\circ} 9.394$ de 20 de dezembro de 1996. Dispõe sobre a Lei de Diretrizes e Bases da Educação Nacional. Recuperado de http://www.planalto.gov.br/ccivil_03/Leis /L9394.htm

Lei $n^{o} 5.371$ de 5 de dezembro de 1967. Autoriza a instituição da Fundação Nacional dos e dá outras providências. Recuperado http://www2.camara.leg.br/legin/fed/lei/19 60-1969/lei-5371-5-dezembro-1967359060-normaatualizada-pl.pdf

Lima, A. C. S. (1992). O governo dos sob a gestão do SPI. In Cunha, M. C. (Org.). História dos índios no Brasil (pp. 155172). São Paulo, SP: FAPESP.

Luciano, G. S. (2006). O Índio Brasileiro: o que você precisa saber sobre os povos indígenas no Brasil. Brasília, DF: MEC/SECAD; LACED; Museu Nacional.

Markus, C. (2006). Identidade étnica e educação escolar indígena (Dissertação de Mestrado). Universidade Regional de Blumenau, Blumenau. Recuperado de http://bdtd.ibict.br/vufind/Record/FURB 5 cfbf40f7d8903b7b7d65a49479908dc

Matos, M. H. O. (2006). Rumos do movimento indígena no Brasil contemporâneo: experiências exemplares no Vale do Javari (Tese de Doutorado). Universidade Estadual de Campinas, São Paulo, Brasil. Recuperado de http://www.repositorio.unicamp.br/handle/ $\underline{\text { REPOSIP }}$

Melià, B. (1979). Educação indígena $e$ alfabetização. São Paulo, SP: Loyola.

Oliveira, H. (1947). Coletânea de leis, atos $e$ memórias referentes ao indígena brasileiro. Rio de Janeiro, RJ: Impressa Nacional. Recuperado de http://www.funai.gov.br/arquivos/conteudo /cogedi/pdf/Livros/Coletanea-da- 
Legislacao-Indigenista-Brasileira008/1\%20-\%20Inicio.pdf

Oliveira, J. (2012). Da negação ao reconhecimento a educação escolar indígena e a educação intercultural: implicações, desafios e perspectiva (Dissertação de Mestrado). Escola Superior de Teologia, São Leopoldo. Recuperado de http://dspace.est.edu.br:8080/jspui/handle/ BR-SIFE/322

Oliveira, M. O. (2004). Identidade $e$ Interculturalidade: história e arte Guarani. Santa Maria, RS: UFSM.

Oliveira, J. P., \& Freire, C. A. R. (2006). A presença indígena na formação do Brasil. Brasília, DF: MEC.

Parecer CEB $n^{\circ} 14$ de 14 de setembro de 1999. (1999a). Aprecia as diretrizes curriculares nacionais da educação escolar indígena. Recuperado de http://portal.mec.gov.br/cne/arquivos/pdf/1 999/pceb014_99.pdf

Pinheiro, P. M. (2012). A construção da escola Apyãwa/Tapirapé a partir das práxis de professores em formação na licenciatura intercultural indígena $d a$ Universidade Federal de Goiás. (Dissertação de Mestrado). Universidade Federal de Goiás, Goiânia. Recuperado de http://www.sbpcnet.org.br/livro/63ra/conpe ex/Mestrado/trabalhos-mestrado/mestradopatricia-magalhaes.pdf

Portaria Interministerial $n^{o} 559$ de 16 de abril de 1991. Dispõe sobre a educação escolar para as populações indígenas. Recuperado https://www.cimi.org.br/2004/06/21816/

Portaria Ministerial $n^{\circ} 60$ de 8 de julho de 1992. Institui e dispõe sobre o comitê de educação escolar indígena junto ao departamento de educação fundamental e médio do Ministério da Educação.
Recuperado de

https://www.cimi.org.br/2004/06/21818/

Ribeiro, D. (1964). A política indigenista brasileira. Rio de Janeiro, RJ: Edições.

Referencial curricular nacional para as escolas indígenas. (1998). Brasília, DF: MEC. Recuperado de http://www.dominiopublico.gov.br/downlo ad/texto/me002078.pdf

Resolução CEB $n^{\circ} 03$ de 10 de novembro de 1999. (1999b). Fixa as diretrizes nacionais para o funcionamento das escolas indígenas e dá outras providências. Recuperado de http://portal.mec.gov.br/cne/arquivos/pdf/r ceb03_99.pdf

Santana, J. V. J. (2011). Reflexões sobre educação escolar indígena específica, diferenciada e intercultural: o caso Kiriri. C\&C - Revista Eletrônica da Fainor, 4(1), 102-188. Recuperado de http://periodicos.uern.br/index.php/context o/article/view/1033

Silveira, E. D., \& Silveira, S. A. D. (2012). Direito fundamental à educação indígena. Curitiba, PR: Juruá.

Sirqueira, E. M., \& Sousa, N. M. (2005). A atuação do Serviço de Proteção ao Índio e a História Guarani/Kaiowá. In Anais do Simpósio Nacional de História (pp. 1-8). Londrina, PR, Brasil. Recuperado de http://www.anpuh.uepg.br

\footnotetext{
${ }^{\mathrm{i}}$ Adotamos neste artigo o ponto de vista dos que aqui viviam.
} 
Feitosa, L. B., \&, Vizolli, I. (2019). Violência, luta e resistência: historicidade da educação rural à educação escolar indígena...

\author{
Informações do artigo / Article Information \\ Recebido em : 02/12/2018 \\ Aprovado em: 22/03/2019 \\ Publicado em: 28/05/2019 \\ Received on December 02nd, 2018 \\ Accepted on March 22th, 2019 \\ Published on May, 28th, 2019 \\ Contribuições no artigo: Os autores foram os \\ responsáveis por todas as etapas e resultados da \\ pesquisa, a saber: elaboração, análise e interpretação dos \\ dados; escrita e revisão do conteúdo do manuscrito \\ e; aprovação da versão final a ser publicada.
}

Author Contributions: The authors were responsible for the designing, delineating, analyzing and interpreting the data, production of the manuscript, critical revision of the content and approval of the final version to be published.

Conflitos de interesse: Os autores declararam não haver nenhum conflito de interesse referente a este artigo.

Conflict of Interest: None reported.

\title{
Orcid
}

Leni Barbosa Feitosa

(iD) http://orcid.org/0000-0001-7333-5264

Idemar Vizolli

(iD) http://orcid.org/0000-0002-7341-7099

\section{Como citar este artigo / How to cite this article}

APA

Feitosa, L. B., \& Vizolli, I. (2019). Violência, luta e resistência: historicidade da educação rural à educação escolar indígena. Rev. Bras. Educ. Camp., 4, e6233. DOI: http://dx.doi.org/10.20873/uft.rbec.e6233

\section{ABNT}

FEITOSA, L. B.; VIZOLLI, I. Violência, luta e resistência: historicidade da educação rural à educação escolar indígena. Rev. Bras. Educ. Camp., Tocantinópolis, v. 4, e6233, 2019.

http://dx.doi.org/10.20873/uft.rbec.e6233

DOI: 